\title{
Arabic in Foreign Language Programmes: Difficulties and Challenges
}

Fatma Y. Al-Busaidi*

Sultan Qaboos University, Sultanate of Oman

\begin{abstract}
The purpose of this study was to review the reported literature regarding Arabic language programmes. It gives an overview of the historical background of Teaching Arabic as a Foreign Language (TAFL) programmes. It also provided a brief description of the Arabic language and its characteristics, and how they might cause some difficulties. Specifically, the diglossic phenomenon in Arabic programmes and how Arabic programmes deal with diglossia was discussed. Pedagogical factors, such as the lack of clearly articulated objectives in TAFL, the lack of coordination between Arabic programmes, the lack of experienced and qualified teachers, the shortage of materials and resources and insufficient presentation of Arab culture in (TAFL) programmes were also discussed.
\end{abstract}

Keywords: Teaching Arabic as a foreign language, MSA, NSA, linguistic factors, pedagogical factors, diglossia.

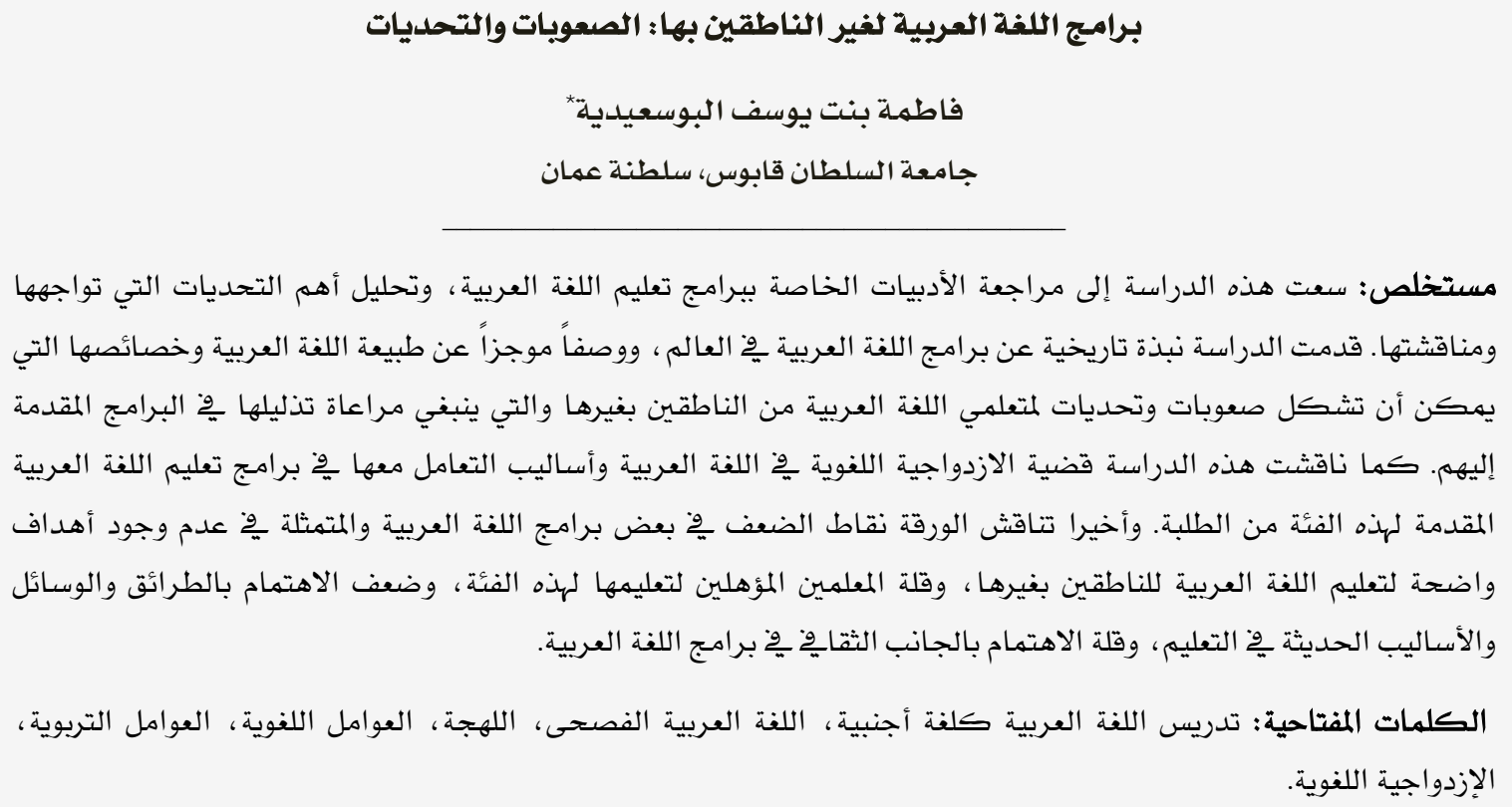

fbusaidi@squ.edu.om* 
The developments in the 1940s in the field of foreign language education had a strong influence on teaching Arabic. This influence began to be evident in the 1950s, under the support of the Ministry of Education of Egypt. For example, Egyptian professors began to conduct a number of programmes and activities such as conferences, seminars and discussions regarding the teaching of Arabic to non-native speakers. All these activities led to the establishment of a number of institutions for teaching Arabic as a foreign language in both Arab and non-Arab countries. The most important institutions founded in the period of 19581979 in Arab countries were as follows:

- Centre for Arabic studies, Lebanon, 1958.

- The Arabic Unit of the Language Centre, Kuwait University, 1965.

- The Institute of Teaching Arabic, Islamic University of Medina, 1965.

- Habib Bourguiba Institute, Tunis, 1968.

- Centre of Arabic Studies at the American University in Cairo, 1974.

- Khartoum International Institute in Sudan under the support of the Islamic Educational, Scientific and Cultural Organisation (ISESCO), 1974.

- Institute of Arabic Language, King Saud University in Riyadh, Saudi Arabia, 1975.

- Institute of Arabic Language, University of Umm Al Qura, Maakkah Al- Mukarramah, Saudi Arabia, 1979.

Following these initiatives, a number of institutions in various Arab countries established private Arabic schools. Thus, currently there are a number of private Arabic programmes for non-native speakers in Morocco, Tunisia, Egypt, Lebanon, Palestine, Jordan, Syria, Saudi Arabia, Kuwait, Qatar, United Arab Emirates, Yemen and Oman.

The growth of awareness in teaching and learning Arabic is not limited to Arab countries. For example, teaching Arabic has a long history in Britain and Ireland, and the language is currently being taught in many of its universities and institutions. Other European countries, the United States of America, and many Islamic countries have witnessed an increase in institutions that teach Arabic for Iislamic purposes (Al-Batal, 1995a). For example, Arabic teaching started in universities in the
United States as early as the $17^{\text {th }}$ and $18^{\text {th }}$ centuries. McCarus (1992) described the history of Arabic teaching in the United States in the following way: "Arabic was being taught in the United States over a century before the signing of the Declaration of Independence, introduced to complement the study of Hebrew and the Old Testament" (p. 207).

In fact, efforts to improve teaching Arabic as a foreign language (TAFL) in America began in 1958 when the Social Science Research Council sponsored a conference of 20 teachers of Arabic to make recommendations in the field, specifically relating to textbooks and the evaluation system (McCarus, 1987). Based on these suggestions, the American Association of Teachers of Arabic (AATA) was established in 1963 under the direction of the Modern Language Association (MLA). Soon after its establishment, AATA began publishing a newsletter, An-Nashrā, 'which later became AlArabiyya (Al-Batal, 1995a).

The AATA made a great effort to encourage study, criticism, and research in the field of TAFL in both linguistics and Arabic literature. Additionally, in order to improve the quality of Arabic programmes across America, the AATA planned to assemble a textbook evaluation package, designed to distribute information on textbooks and other materials to teachers of Arabic. The idea for this package came from a survey conducted with financial support from the Ford Foundation channelled to the National Council of Less Commonly Taught Languages. This study focused on the institutional setting of Arabic language teaching in the United States (Belnap, 1995).

The AATA also developed the Arabic language learning framework. Thus, they conducted studies to better understand the nature and variety of existing Arabic curricula. In addition, while American universities and institutions were unlikely to settle on a particular Arabic curriculum for non-native speakers, they worked to produce a set of universal curriculum strategies meant to serve as a resource for teachers and learners (McCarus, 1987).

Furthermore, in response to and as a consequence of the increasing interest in the Arabic language, a number of universities and colleges in America and Europe, and many Islamic from countries such as Malaysia, Indonesia, and India expanded and added new courses to their Arabic programmes. Moreover, in order 
to provide English-speaking learners of Arabic with the opportunity to study the language in its real cultural setting, several universities conducted intensive summer language programmes in the Arab world to foster Arabic study abroad (Al-Batal, 1995a).

\section{Major concerns for the field of TAFL}

Despite all of the efforts to produce Arabic language programmes worldwide, the field of TAFL still has major concerns. For example, although in 1974 the United Nations adopted Arabic as one of its six official languages, the National Foreign Language Centre considered Arabic to be one of the less commonly taught languages in America, the United Kingdom and even in the Arab world. Ryding (1994) highlights this issue, stating that: "When considering some of the facts about Arabic, it may be surprising that it is one of the less commonly taught languages in the West in general and in the United States in particular." (p.23).

Similarly, Allen (2007) confirms the lack of attention given to Arabic in the United States: "The events of 9/11/2001 found American 'preparedness' in terms of Arabic-competent citizens at a very low level." (p. 258).

However, this changed after the terrorist attacks of September 11 2001. Allen (2007) explains this as follows:

Since that day, the status of Arabic in the national consciousness has been transformed almost overnight to become the number-one desideratum of the American government and its various agencies. Huge amounts of money are being spent and will be spent in an attempt to produce an increased number of Americans who are competent in the Arabic language at levels considerably higher than those of the majority of previous learners of the language. ( $\mathrm{p}$. 258).

Although the Arabic language has attracted interest in the United States and huge sums of money are being spent to improve its teaching in Arab and non-Arab countries, challenges facing the field of teaching Arabic for non-native speakers seem to be an issue for many researchers. For example, one of these issues is the significant lack of Arabic language competence among non-native speakers. Al-Batal and Belnap (2006), for instance, found that an extremely small number of foreigners engage in Arabic language learning in U.S. universities in contrast to other languages, and very few of them achieve a high level of proficiency.

The United States Foreign Service Institution (FSI) has classified languages into four levels or degrees of difficulty based on the amount of time required to reach a certain level of proficiency (Liskin-Gasparro, 1982). According to the FSI rankings, Arabic is grouped with those relatively difficult languages such as Chinese, Korean and Japanese (Stevens, 2006). It has been argued that Arabic cannot be fully learned as a second or foreign language to a level where a learner would be able to be at the educated native speaker level. As a result, there has been a serious argument over whether or not non-native learners can ever achieve the highest level, level 5, in Arabic (in terms of FSI proficiency ratings) (Ryding, 1994). Likewise, it has been found that some Arabic teachers consider this level of achievement simply not possible (Ryding, 1995).

Belnap (1987) conducted a study to investigate the number of students who learned Arabic in the United States and to find out what motivated them to learn this language. The results showed that the number was on the rise; however, the great majority did not continue their study of the language beyond the second year. Another study conducted by Belnap (2006) to understand students' beliefs and attitudes towards the Arabic language indicated that more than half of students felt that Arabic was a difficult language to learn and achieving a high level of proficiency was difficult. Moreover, a study by Abdelhadi, Ibrahim and Eviatar (2011) found that learning the written form of Arabic took a longer compared to other languages.

In order to understand more, many researchers (e.g. Al-Batal \& Belnap, 2006; Belnap, 2006; Stevens, 2006; Wahba, 2006; Palmer, 2008; Fragman \& Russak, 2010; Abdelhadi, Ibrahim \& Eviatar, 2011; Myhill, 2014) began to investigate the factors influencing this issue. The majority of these studies reported that there are general problematic factors that lead to Arabic being considered a difficult language to acquire. Their findings can be grouped into 
two main categories: firstly, linguistic difficulties which might well be understood by reviewing the literature relating to the characteristics of the Arabic language; and secondly, difficulties related to pedagogical factors, such as the qualities and the characteristics of Arabic programmes, the quality of teachers and the teaching materials used. All of which will be discussed in the following sections.

\section{Linguistic factors affecting teaching and learning Arabic as a foreign anguage}

Arabic is the official language of some twenty nations, stretching from the Atlantic coast of North Africa in the west to the Sultanate of Oman in the east, and from Syria in the north to Sudan in the south. Arabic belongs to the Semitic group of languages, and it is a synthetic rather than an analytic language. Therefore, there are significant differences between the structures of Arabic and Indo-European languages, such as English, Spanish, French, and German. Hence, Arabic has some characteristics that European languages do not, along with a very complex morphological system (Holes, 1995).

To understand the linguistic factors that affect the learning and teaching of Arabic and how it is different from other languages, a brief overview of its characteristics is necessary. Firstly, a discussion of the phenomenon of 'diglossia' in Arabic is in order.

\section{Phenomenon of diglossia}

The Arabic language is widely characterized by diglossia. Ferguson (1959) has defined diglossia as:
A relatively stable language situation in which, in addition to the primary di- alects of the language (which may in- clude a Standard or regional stand- ards), there is a very divergent, highly codified (often grammatically more complex) superimposed variety, the ve- hicle of a large and respected body of written literature, either of an earlier period or in another speech community, which is learned largely by formal edu- cation and is used for most written and formal spoken purposes but is not used by any sector of the community for or- dinary conversation. (p.334).

Two forms of Arabic are in use, namely Modern Standard Arabic (MSA) and Non-Standard Arabic (NSA). Whilst being closely related, they are nonetheless quite different. As a result, diglossia has often been described as being the 'bilingualism of a monoglot'. Some professionals in the field go beyond this and state that all Arabs are bilingual, as they believe that Arabs are native speakers of NSA and not MSA (Eisele, 2006; Palmer, 2008).

Until a few decades ago, this was the type of Arabic most commonly taught in American and European universities (Versteegh, 2006). Although this level of Arabic is still used in some TAFL programmes, it is restricted to religious and highly formal contexts.

The second form of Arabic is Modern Standard Arabic (MSA). It is a direct descendant of classical Arabic and, until recently, it was the language of important discourse, contemporary literature, and the media (newspaper, radio, television, and the Internet). It is also the language that is used in formal situations such as speeches and public lectures. MSA is a formal, mostly written language, which is not used for daily communication. There are no native speakers of MSA, but educated people in the Arab world learn this form during formal education (Versteegh, 2006).

However, this kind of language has produced a new form of comprehensible spoken Arabic called 'Educated Spoken Arabic' (ESA). Educated Arabs of most nationalities use ESA as a way to communicate verbally for interdialectal conversation, social discussions and other occasions when dialects are considered too informal and literary Arabic is too formal. The pronunciation of ESA is very closely related to that of MSA and it has an exceedingly classical vocabulary. There are differences however, in some aspects of syntax and morphology (Harvey, 1979).

The third form of Arabic is called Colloquial Arabic or Non-Standard Arabic (NSA). This refers to regional dialects used in everyday conversations and popular cultural media. There are in fact many different Arabic dialects, which vary not only from one country to another, but also from one region to another within one country (Cote, 2009).

There are significant differences in structure and vocabulary between MSA and NSA at all linguistic levels. (Ferguson, 1959; Versteegh, 2006; Cote, 2009; Myhill, 2014). Although many other languages have formal and informal variations, the differences between formal 
and informal Arabic are substantially greater than those in European or any other language (Eisele, 2006; Myhill, 2014).

Even in cases where MSA and the NSA share some lexical items, the vowels may be different. For example, the word yktub (he writes) is pronounced yaktubu in MSA, but yktib in NSA. This means that learning a certain word in Colloquial Arabic does not necessarily mean that it will be the same in the written form. Van Mol (2006) argues that the major challenge for foreign learners of Arabic is that they have to learn at least two varieties of the language. This means that they have double the vocabulary to learn, as it is very common in Arabic to find different word meanings in different dialects, including Standard Arabic. It also causes the problem of needing to teach two different pronunciation systems to students at the same time, one for NSA and one for MSA (Abu-Hatab, 1992).

This can be better understood if we consider that the effect of diglossia is not only limited to non-native learners but also to native speakers themselves. For example, numerous studies have found that diglossia in Arabic has hindered the process of literacy acquisition among native Arabic speakers because of the linguistic distance between the spoken dialects and the standard written form. Confusing might re-word. "Young Arab users do not feel that they are free to use and innovate in [MSA]. Pupils entering school have to 'unlearn' or even suppress most of their linguistic habits while they try to acquire a new set of 'rigid' rules." (p. 41). This is because, "[MSA] is nobody's mother tongue and is rarely or almost never used at home in the Arab world" (Maamouri, 1998, p. 33).

\section{Diglossic phenomenon in Arabic pro- grammes}

Although some previous research has attributed poor student proficiency in Arabic to diglossia, there are other factors that affect the learning of this language which need to be taken into account. The central one is how Arabic programmes deal with diglossia.

The literature in this field indicates that, as yet, there is no clear agreement on how to deal with the diglossic phenomenon. The questions of what kind of Arabic to teach and what kind of Arabic might be more practical to offer are the biggest challenges facing Arabic programme designers (Alosh, 1997; Ryding, 2006; Palmer, 2008; Myhill, 2014). As a result, a variety of approaches have emerged from different schools. These approaches will be highlighted in the next section.

\section{Teaching modern standard Arabic}

This approach only emphasizes the teaching of Modern Standard Arabic. Many scholars consider MSA to be the only form of the language worth teaching. Maamouri (1998) stated that "standard was the 'real language,' and that all other varieties of it were 'degenerate' and 'corrupt' versions" (p. 33). This philosophy is present today both inside and outside of the Arabic-speaking world.

The proponents of this view state that MSA is the level of language that educated Arabs are able to understand in the different Arab countries. It is also the language that combines the needs of foreign learners who want to know the cultural, religious, and artistic inventions of the particular Arab country? Finally, it is the form that is most likely to remain with learners when they return to their home countries or when they travel to any Arab country, as it can be used for oral communication anywhere in the Arab world where communication is difficult in the local dialect (Ryding, 1995; Nahla, 2006).

However, this approach has some limitations, and a negative impact on learners in many aspects. Firstly, it does not take into account the fact that Arabs themselves would never use this kind of Arabic in their everyday activities, such as informal conversation and shopping (Ryding, 1995; Younes, 1995; Alosh, 1997; Palmer, 2008). As a result, as argued by Wahba (2006), teaching this form has led to even the more advanced students experiencing a gap between their classroom achievement and the ability to integrate linguistically and culturally into Arab society. Similarly, Heath (1990) found that students who have only studied this form of Arabic do not feel integrated into society and often experience disappointment and embarrassment when trying to converse with Arabic speakers. He argues, "teaching students only MSA severely hampers their ability to communicate in the language they have striven so hard to learn. Given that Arabs will understand what such students are saying, the students themselves 
will not understand anything said to them outside the limited MSA linguistic register they have mastered." (p. 43).

Moreover, Al-Batal (1992) found that most students who learn this form of Arabic get easily discouraged and frustrated, and give up after one year because they do not have the ability to use the language in daily communication.

Another argument against this approach is that it ignores those students who want to learn Arabic for speaking purposes only. A survey from the National Middle East Language Resource Centre (NMELRC) found that over 650 students learning formal Arabic at U.S. institutions of higher education were mainly interested in learning spoken Arabic (Belnap, 1987). This finding was confirmed by a study conducted by Younes (1995), who found that the majority of students were learning Arabic to be able to communicate in the Arab world.

Finally, the proponents of this approach do not include dialect courses in Arabic programmes because they believe that the classroom is not an effective environment in which to produce proficient speakers. It was generally accepted that students who wanted to acquire an Arabic dialect could do so naturally through interacting with local people (AlHamad, 1983). However, from another perspective, students should receive preparation for learning Arabic dialects in the classroom by a specialist teacher before they start to converse with people who might use different dialects and accents. The supporters of this view believe that Arabic teachers should play a vital role in helping learners function within a diglossic environment. Additionally, teachers should help students understand the difference between the two forms of Arabic in order to avoid any confusion that might result (Al-Juhany, 1990; Palmer, 2008).

\section{Teaching colloquial Arabic}

Developments taking place in the field of teaching and learning foreign languages have led to some improvements in the Arabic teaching profession. One of the most significant improvements is the increased interest in the communicative competence approach, which is believed to lead to the oral proficiency of students (Al-Batal, 1992; Younes, 1995; Alosh, 1997; Wahba, 2006). However, this approach seems to be applied differently by different schools. The differences are further examined as follows:

\section{- Ignoring standard Arabic and teaching a selected dialect}

This approach ignores Standard Arabic and teaches a selected dialect in order to enable students to become involved in the activities of daily life. This approach has also led to another problematic issue regarding dialect to teach, as very often the chosen dialect might well not be understood by people living in other Arab countries (Alosh, 1997). Moreover, the negative aspect of this approach is that it does not address the needs of those who want to learn the written form of Arabic. Al-Batal (1995b) provides two strong arguments to support this view. Firstly, he refers to a survey conducted by Belnap (1987) indicating that some students of Arabic are interested in developing overall language proficiency. This means that there is a significant need for including MSA in any programme, at least for developing literacy abilities. Secondly, he concurs with Allen (1987), who maintains that no Colloquial Arabic programme is likely to take learners beyond the basic level.

Although the teaching of Arabic dialects has become on approach in TAFL, very few programmes in the Arab world or in other countries for that matter offer this because of both logistical limitations and ideological reasons. Suleiman (2003), for example, clarified that any attempt to limit MSA in curricula and place emphasis on a spoken variety may be seen as a threat. Additionally, Palmer (2008) reported that there are numerous obstacles to introducing spoken Arabic. He suggests that issues of prestige, the preservation of the Quranic language, and integration are often cited as significant concerns that limit the idea of providing dialects in Arabic programmes. Therefore, at a philosophical level, some educators in the field believe that dialects are the poor relations of the standard written language and are, therefore, not useful in Arabic programmes. At a practical level, the programmes that see the value of offering classes in Arabic dialects may not have the required teachers and learning materials that lead to success (Alosh, 1997). 


\section{- Adoption of educated spoken Arabic}

There is another approach which calls for the adoption of 'Educated Spoken Arabic'. This form represents a viable option for the development of spoken proficiency because it is understood by most educated Arabs in Arab countries (Wahba, 2006). Although this has become the language of choice for some Arabic programmes, it is still not the form that suits those learners who prefer to achieve basic proficiency in the written form of Arabic. This has led many institutions to consider other approaches.

\section{- Providing two successive courses}

Some programmes provide two courses. Students first study MSA and then, in a second course, they learn a chosen dialect. Proponents of this view believe that allowing students to become familiar with MSA is a good start for learning a dialect (Al-Hamad, 1983). However, others argue that it is best to start with the dialect because it theoretically reflects the order of acquisition of native speakers, who first learn the dialect, and later at school, learn Standard Arabic (Nicola, 1990; Ryding, 2006; Younes, 1995). Consequently, some researchers argue that the starting point should focus on building a dialectal foundation in listening and speaking, and then the MSA form should be gradually introduced. Although such an approach is consistent with the way Arabic is learnt and used by native speakers, the major problem is the time limitation. Students usually do not have time to master an Arabic dialect and then start MSA. Another criticism is that the Colloquial Arabic portion of the course focuses only on listening and speaking skills, which may result in students leaving the programme with no ability to read or write (Younes, 1995).

\section{- Teaching both standard Arabic and a dia- lect simultaneously}

Some educators believe that students should learn both forms at the same time. For example, Younes (1995) writes: "If the goal of an Arabic-as-a-foreign-language programme is to prepare students to function successfully in Arabic, then they should be introduced to both a Spoken Arabic dialect and "formal Arabic" from the beginning of an Arabic course" (p.233).
Additionally, Al-Batal (1992) proposed an alternative approach where both Colloquial Arabic and MSA are taught in the classroom. This reflects, he suggests, the linguistic reality in the Arab world today. As a result, some institutions such as the Foreign Service Institute (FSI) began to design a curriculum that develops communicative competence simultaneously with Modern Standard Arabic (Ryding, 2006). Also, the University of Cambridge adopted the communicative approach to help the students speak colloquial Arabic (Palestinian Arabic) from the very start of the course (Dickins and Watson, 2006). In addition, the communicative approach has been introduced in the Arabic programmes in Britain and Ireland, and most universities have moved to more communicatively oriented materials such as "Elementary Modern Standard Arabic" and "al-Kitab fi Ta'allum al-'Arabiyya". Furthermore, to enable learners of Arabic to understand and express themselves in the local dialects along with the MSA, the majority of Arabic programmes in the Arab world such as Yarmouk University programme in Jordanian, Sultan Qaboos College for Teaching Arabic to Non-Native Speakers programme in the Sultanate of Oman, and The American University programme in Cairo, have adopted this approach.

Such an approach encompasses all language aspects, with each being afforded enough time. These aspects are related to the four language skills of listening, reading, writing and speaking. In these programmes, reading and writing are taught in Mmodern Standard Arabic and speaking and listening in a dialect (Holes, 1995). However, it has been argued that this approach has led to some problems and confusion for some learners of Arabic, especially for those at the beginning stages of learning (Al-Hamad, 1983). Some even think that although the MSA and dialects are, to some extent, related, they are still so different that learning them is similar to learning two different languages simultaneously (Stevens, 2006). This could be more easily understood if one keeps in mind that in learning languages, what one learns in conversation frequently supports and assists what one learns in reading.

However, Ryding (2006) found that programmes that provide both forms, formal and informal, do not inhibit the attainment of read- 
ing and writing skills, as they very often reinforce each other. Nevertheless, he confirms that the achievement of advanced proficiency will take more time and need more focus. With the same perspective, Agius (1990) found that students who were exposed to both varieties of Arabic simultaneously seemed to be much more motivated to learn the language than those who had studied in the traditional way.

In sum, aAfter providing a brief definition of diglossia in the Arabic language and the teaching approaches developed, the following sections will provide a description of orthography, morphology and the Arabic phonetic system, and how they might createcause some challenges for students of Arabic.

\section{Arabic orthography}

The Arabic writing system is an alphabetic logographic script, where every letter is assembled in order to generate meaning. The alphabet consists of twenty-eight letters without the inclusion of hamzah. Moreover, three letters are treated as long vowels (sounds): 'alif' (I), 'waw', (و) and 'yaa', (ي) which represent the sounds /a: / / u: / and / i: / respectively in English.

Arabic script is cursive, meaning that certain letters must be connected to others in writing. There are no capital letters in Arabic, but a letter may occur in more than one form depending on its position in the word and what letters surround it. Every letter has four different forms: isolated, initial, medial and final. However, the basic letter remains unchanged. Some Arabic letters are attachable only to the letters preceding them, and some are attachable to letters preceding and following them (Awde \& Samano, 1986; Saiegh-Haddad \& Henkin-Roitfarb, 2014).

The findings of some previous researchers, such as Al-Mutawa (1995), Al-Juhany (1990), Hansen (2010) and Abdelhadi, Ibrahim and Eviatar (2011) have revealed that dimensions connected with the letter architecture, and the fact that the majority of the letters have multiple shapes, are connected to adjacent letters, and are often distinguished from one another on the basis of the number and location of dots alone, contribute to the difficulty in learning the Arabic language. Fragman and Russak (2010), for example, examined the Arabic spelling accuracy of native Hebrew adoles- cents in the eighth grade and found orthographic sources of difficulty. He reported that pupils made spelling errors, as they were confused by similar looking Arabic letters, which are at times differentiated only by dots. In addition, they were confused between letters with multiple shapes. In some cases, the letters looked similar to others. Vanderhoof (2011) also reported a lack of improvement in the overall spelling performance of 44 adult English as a Second Language (ESL) students.

Likewise, features of Arabic orthography constitute a major difficulty for the foreign language learner since Arabic, in contrast to European languages, is read and written from left to right and uses completely different scripts and directionality. It has been found that this is cognitively complex and requires restructuring one's way of thinking (AlJuhany, 1990).

Furthermore, Arabic also has three short vowels which may be represented by diacritic marks above or below a letter with the same sound of alif, waw and yaa. The signs of these three vowels are, respectively: fathah (j) a small diagonal stroke above a consonant, dhammah (\$) a small waw above a consonant, and kasrah' (9) a small diagonal stroke under a consonant (Awde \& Samano, 1986; Fragman \& Russak, 2010).

Al-Mutawa (1995) found that the majority of learners of Arabic faced difficulty in differentiating between short and long vowels which created pronunciation, reading and writing difficulties.

In addition to the three vowel signs, there are another two significant signs called sukūn and shaddah. The former refers to a small circle written above the letter and indicates the absence of a vowel after a consonant; its sign is (). On the other hand, when a consonant occurs twice without a vowel in between, it is written only once with the sign (b) shaddah. The letters which have shaddah are commonly called müdhaaf. This means that the letter should be doubled in pronunciation. Attadheef ' التضعيف has a great impact on the meaning of the words in Arabic. For example, if you say Faāla, ' لè' it means 'did' but with the attadheef ' ل'e' it means 'activated'. Therefore, some researchers (e.g. Al-Mutawa, 1995; Abdelhadi, Ibrahim \& Eviatar 2011) stress the importance of helping Arabic students understand and perceive the idea of doubling consonants. 
The positions of Arabic letters and the complicated marks appearing above or under them can cause some challenges for Arabic learners. What makes the situation worse is that, unfortunately, in most modern written and printed Arabic, no signs (marks above or under letters), sukūn 'سكون' or shaddah ' ثدة are used to help while reading. This might be one reason for the delayed development of reading skills of Arabic learners (Al-Mutawa, 1995).

Another commonly known problem of written Arabic is hamzah (هم). Burj (1978) states that the rules governing hamzah are so complicated and vary according to its position within the word, that they cause problems not only for foreign learners, but also native speakers of Arabic. Moreover, Al-Juhany (1990) argues that the way hamzah is presented to students in Arabic programmes and the teaching methods used add to the complexity of this issue. He further states that this matter needs expert and well-trained teachers provided with educational resources.

Moreover, in Arabic, there are two different systems for definite and indefinite nouns. Firstly, a definite noun is indicated by the definite article, al-atareef corresponding to the word 'the' in English and appearing with the noun as one word. Although the definite article always has the same written shape, its pronunciation differs depending on the following letter, which can lead to some confusion if not taught well (Al-Mutawa, 1995). Secondly, nouns and adjectives can also be indefinite when the vowel signs for one of three case endings, called in Arabic tanwin ' لتنوين', appear at the end of the word and make double short vowels. There are three tanwin in Arabic: tanwin adham, tanwin alfatah and tanwin alkasr. This means that they are to be pronounced with a final (n) but not written as an (n), for example, /kitabun/ كتابّ / كتابا / /kitababin / كتاب:

The issue of using the nunation (or tanwin ' 'التنوين ) in Arabic leads to some challenges in reading, writing and pronunciation if the text is not marked, especially for beginner learners who are not familiar with Arabic grammar. Therefore, learners must know which tanwin they have to use to produce the correct meaning (Al-Tueriqy, 1988; Ibrahim, Khateb \& Taha, 2013).
Although the majority of the words are spelt exactly as they are pronounced in Arabic, spelling has very often been reported as problematic. Many researchers (e.g. Burj, 1978; AlJuhany, 1990; Fragman \& Russak, 2010) found that students struggle with Arabic spelling. Noticeably, spelling problems in Arabic do not occur, as is the case in the spelling of English or other European languages, out of irregularities in the sound-symbol relationship. Instead, they arise from learner inability to distinguish between some Arabic sounds whose pronunciations to some extent look/sound similar to non- native learners, for example $(b / t /)$ and $(ت / t)$.

\section{Arabic morphology}

Arabic, like all Semitic languages, is characterized by the use of certain morphological patterns. Thus, the majority of Arabic words are derived from, and can be analysed from their roots, which represent meaning. These roots usually consist of three consonants, which form the basis for the formation of numerous words not necessary. In other words, by using the three consonants of the root and by varying the vowel of the simple root, and adding prefixes, infixes, and suffixes, according to certain consonants, the actual words are produced. For example, the following derivations can be made from the root KTB, 'كتب (write):

/ كاتب / مكتوب / maktib/ub/ 'writer', 'something written', مكتبة /maktaba/ 'library', مكتب / maktab/ 'office', كتاب / אناب / kitāb / 'book'.

Some researchers found that the characteristics of Arabic morphology caused difficulties for students of Arabic, as some could not make a link between the new word they learnt and its official root (e.g. Burj, 1978; Al-Juhany, 1990). However, Stevens (2006, p.24) suggests that it is "learnable" and can even make acquiring vocabulary far easier than might be the case in many other languages where derivational patterns are haphazard. In Arabic, it is often not necessary to learn vocabulary as a separate activity because the general character of derivational morphology makes vocabulary learning more straightforward. Nevertheless, this necessitates using teaching methodologies that help familiarise students with these forms. In this case, understanding the root system will make learning and remembering vocabulary easier (Burj, 1978). 


\section{Arabic phonology}

As stated earlier, Arabic differs from other languages in many ways. One of the most crucial differences is the way in which some Arabic sounds are pronounced. It has been widely reported by non-native learners that at least one of the nine sounds presented below caused a problem in their speaking, understanding and even emotional attitude in learning Arabic (Taaima \& Al-Naqa, 2006; Madkoor, 2007). Theses sounds are $(\tau / \hbar /)$, ( $\dot{\tau}$

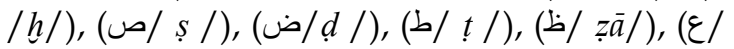

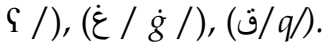

This difficulty mainly results from the fact that there is no equivalent to some of these sounds in English and most other languages. For example, the sound $(\dot{z} / h /)$ has no comparable sound in English. It is something like (kh), pronounced as far back in the throat as possible. $(\tau / \underline{\hbar} /)$ is a peculiarly Arabic consonant. It is a (h) but must be sharply distinguished from the throat. The same thing could apply to

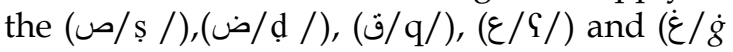
/) which have an equal in other spoken languages (Al-Mutawa, 1995).

In order to produce these sounds, the majority of learners tend to convert them into other sounds that are easier to create or are closer to their native language. Al-Juhany (1990) and Burj (1978) found that this subsequently leads to confusion in student linguistic expression or the loss of the intended expression. Additionally, Al-Mutawa's (1995) findings showed that some learners might be able to produce some of these sounds correctly, but this involves an unnatural exaggeration in the movement of their lips and their articulation in general, which distorts their normal communication.

However, Al-Juhany (1990) proposes that these sounds can be produced by learners if a tremendous effort is made by Arabic teachers to help them recognize stress points. He also argues that the description of sounds cannot be understandable without the use of the technical phonetic methodology used by special Arabic native teachers who have themselves received training in Arabic phonetics.

Additionally, Al-Juhany (1990) suggests that the beliefs of teachers might be another reason for the difficulties in Arabic pronunciation. He states that many teachers think that these consonants are too difficult for foreigners to produce and, therefore, they do not encourage students to learn how to pronounce them. He further argues that although adult learners are less likely to adopt the right Arabic pronunciation, they might have other skills which children do not seem to have which make them motivated to acquire these sounds. He reiterates that these sounds can be produced by Arabic learners if account is taken of the importance of phonetic training programmes and the application of new sound technology.

One of the arguments regarding pronunciation is whether Arabic sounds should be presented using the transliteration method (the practice of using Latin script instead of Arabic script for rendering the language) or by using the Arabic script from the early stage of learning (Al-Juhany, 1990). Supporters of the transliteration method believe that it might provide beginner learners who know no Arabic with some idea of the sound intended. This helps them to avoid the difficulty of writing Arabic until they are familiar with Arabic script. However, as many Arabic sounds are totally unlike those of English or other European languages, the transliteration method can be a phonetically vague approximation. Consequently, students relying on any form of transliteration will be hindered and delay their ultimate grasp of authentic script and the acquisition of sound-script correspondences (Beeston, 1968).

It has also been found that the transliteration method confuses Arabic language learners in writing, speaking and dictionary usage. For example, both the word sāra 'سار' (he went) and șâra 'صار' (to be) are written in the same way in Latin script 'Saara' despite their different meanings. Moreover, using an Arabic dictionary might be more problematic if the learners are not sure of the sound they heard; they might search for another word and get the incorrect meaning (Ibrahim, 2001). What makes the issue more complicated is that some learners may memorise the word with the wrong meaning and when they come to use it, either in speaking or writing, they do so incorrectly. This confusion has been found to lead to some emotional difficulties, as many learners report that very often they are surprised when they discover that the word they learnt had another meaning. Their embarrassment even increases when they fail to convey a clear linguistic message while communicating with others (Taaima \& Al-Naqa, 2006). 
Despite the recurrence of this problem with a great number of Arabic learners, as reported by Madkoor (2007), the majority of student books that are designed to teach Arabic, especially for beginners, are still written in Latin script. This might help beginners to some extent, but it does not provide learners with the intensive strategies necessary to help them overcome the confusion that might appear from mixing up sounds. In addition, it will delay student acquisition of Arabic sounds and scripts (Al-Juhany, 1990).

\section{Pedagogical factors affecting teaching and learning Arabic as a foreign language}

Despite the efforts that have been made by some professionals to develop programmes for TAFL, there are common pitfalls in some of these programmes. These can be summarized as follows:

\section{Programmes lacking clear objectives}

Abboud (1995) states the following: "It is sad to note that after all these years there are still Arabic programmes, and they seem to be the rule rather than exception, that do not have clearly articulated objectives for their sequential language courses" (p.26). In the same vein, Abboud (1995) highlights that Arabic programmes in the Arab world, in general, need to be improved to address this issue. This cannot be achieved unless the goal of learning the language is carefully addressed to cover the need of each group of learners.

Abboud (1995) refers to another significant challenge resulting from not having clear objectives in Arabic teaching and learning programmes. He found that students of Arabic courses complain that when they move from one level to another, or even from one semester to another in these programmes, they are often passed along to teachers who are unaware of what they did in previous courses. Moreover, they can often be presented with materials and methods that have nothing to do with those previously used.

\section{Lack of coordination between Arabic pro- grammes}

Lambert (1992) considers the lack of coordination between Arabic programmes as one of the greatest weaknesses of Arabic language education programmes. He argues that these programmes normally work essentially in isolation from each other. This leads to problems for students who cannot be transferred from one programme to another, and those who begin to study Arabic in one Arab country and cannot carry on their learning in another.

The present dilemma in Arabic teaching is complicated further by the varied quality of language training available in overseas Arabic programmes. Although, as stated by Al-Batal (2007), the Arabic study-abroad experiences of American students tend to be positive in terms of cultural exposure, such programmes frequently lack curricular articulation with their corresponding U.S. institutions, and teachers experience poor faculty training in language pedagogy to assist the needs of American learners. Batal (2007) refers also to the financial issues linked to this. Study-abroad programmes have no funding to bring about curricular changes or provide in-service teacher training and professionalization.

\section{Lack of experienced or qualified teachers}

There is almost complete agreement between professionals that a good teacher is the fundamental element of the TAFL programme. A good teacher can give life to the curriculum and language resources, attract student awareness, raise their curiosity and enthusiasm, and make learning an enjoyable process (Belnap, 1995; Nahla, 2006). However, qualified teachers are still in short supply in the field of Arabic instruction, as pointed out by several researchers (e.g. Nahla, 2006; Nash, 2010). They all agree that many teachers are not equipped with an Arabic teaching methodology that leads to language proficiency and some are not even qualified to teach Arabic to native speakers. Nash (2010) contends that being a native speaker of Arabic is not enough to be able to teach it. Similarly, Belnap (1995), in his evaluative study of Arabic teachers in some Arabic institutions, indicated that none of the teachers at these small institutions had formal training in Arabic teaching. He says that this might be a major reason for the limited number of students achieving high levels of language acquisition in the Arabic language.

Unfortunately, even as late as 2006, the field of Arabic was still lacking in trained professionals. Ryding (2006) states that there are only a small number of people that can be considered professional teachers of Arabic as a foreign language and that "the active membership of 
the American Association of Teachers of Arabic [AATA] currently numbers about 130" (p. 13). Therefore, this has led many universities in the US to not be able to accommodate the increasing numbers wishing to enrol in Arabic programmes.

This challenging issue seems to be associated with the lack of programmes that prepare teachers of Arabic as a foreign language. According to Al-Batal (2007), only one program at the University of Michigan offers a graduate degree in TAFL and, even there, the programme employs only one Arabic specialist.

In Arab countries the situation is similar. Nahle (2006, p.76), for example, states the following: "There is no university in Egypt that has a programme for preparing teachers to teach Arabic to non-native speakers except the American University in Cairo." This is also applicable to other Arab countries (except the Khartoum International Institute in Sudan which began some work on this in 1974). Madkoor (2007) evaluated the few valid programmes in the Arab world, such as those in Egypt and Sudan, and states that they struggle to provide teachers with the skills needed for Arabic teaching. One of the major recommendations was the inclusion of creative modern resources and varied materials in Arabic teacher education.

Al-Mutawa (1995) argues that both native and non-native speakers find challenges in the field of teaching Arabic. She found that although non-native speaking teachers have good education and training, they have problems with the pronunciation of many Arabic sounds. Secondly, some native teachers were found to use their dialects in the classroom and some did not or were not able to pronounce some sounds, either because they do not have those sounds that sound in their dialects or they used different pronunciations.

It has also been found that the majority of teachers of Arabic use traditional teaching methodologies such as memorization, and grammar-translation. Additionally, most of the Arabic courses, including the communicative Arabic courses, are not designed to serve communicative purposes. The focus has always been to understand Arabic grammar and comprehension (Siti Ikbal, 2006).

\section{Shortage of materials and resources}

Although some Arabic programmes in the West and in some Arab countries such as Egypt have introduced materials and resources to support the learning of Arabic, the lack of appropriate materials is a major concern for many professionals in the field. For example, while there are various textbooks, supplemental materials and E-learning programmes available to teach other languages such as English, all these resources are almost completely absent from Arabic programmes (Alosh, 1997; Stevens, 2006; Taaima \& AlNaqa, 2006).

This has led Arabic teachers in many Arab countries to be more dependent on materials available to teach Arabic as a first language. This issue was reported to be one of the major worries of many Arab educators. For example, Al-Batal (2007) found that Arabic teachers have to choose very difficult texts, which are only suitable for native speakers with a high level of Arabic. His findings showed that this matter has made learning the language a challenge and has led learners to suffer psychologically. They go through difficult experiences of disappointment, anxiety and, even worse, they form a negative attitude towards learning Arabic.

This problem was reiterated by some researchers (e.g. Allen \& Allouche, 1986; AlBatal, 1992) who found that it is difficult to find appropriate teaching materials in the Western context. This forces many AFL teachers to develop their own curriculum and materials to suit the particular needs of American students of Arabic

Versteegh (2006) added that there is a need for a reliable grammar reference. He found that most students had to make use of the oldfashioned grammar of classical Arabic. He also stated: "lexicographical tools are still a problem; the dictionaries that are published in the Middle East, especially in Lebanon, tend to focus on the classical language and are less practical for beginner students" (pp.9-10). Therefore, the only option available for students is an Arabic / English dictionary, which does not help those who do not speak English.

Additionally, the limitation of educational resources for developing is another major concern. The dialects of Arabic are not written down, and as they are different from one 
country to another, it is very difficult to produce dialect resources for all these different dialects (Al-Batal, 1992, 1995b; Wahba, 2006).

\section{Insufficient presentation of Arab culture}

It has been widely agreed that culture and language are entangled. Many researchers in the TAFL field (e.g. Al-Batal, 1988; Suleiman, 1993; Elgibali \& Taha, 1995; Taha, 2006) have emphasised that cultural competence is one of the important factors of language competence. Therefore, they highlighted the significance of building a curriculum that helps students to understand religion, history, politics, and other issues related to Arabic culture. They found that students with knowledge of these important aspects of Arabic culture were more able to get involved with people and more confident in using the environment surrounding them.

Belnap's (1995) findings confirmed that cultural proficiency has regained prominence as a primary objective of language learning, as the majority of students in his research placed cultural understanding among their primary reasons for studying the language. Similarly, Nahla (2006) found that many students believe that learning Arabic in Arab countries is more helpful than learning it in non-Arabic speaking countries. The learners believe that learning Arabic in Arab countries gives them the opportunity to learn valuable information with regard to Arab society in terms of how people live, how they deal with each other, what interests them, and what makes them happy, sad or angry. In addition, this presents a good opportunity for learning local stories, anecdotes, and the views of Arabic-speaking people towards the world around them.

Anghelescu's (2006) work indicates that students who studied Arabic in a programme in which cultural understanding was ignored faced challenges, even at advanced levels. She states that the issues of cultural and linguistic discontinuity hinder potential learners from the outset. She also cites Killean (1997), who argues that the difficulties of learning Arabic in the West pertain not only to the language system, but also to the cultural foreignness felt by the learners.

In the same vein, Nahla (2006) found that foreign learners of Arabic studying in Egypt who were not provided with any cultural under- standing in their Arabic course reported social difficulties in dealing with unfamiliar social customs. This was one reason cited for some of them being unable to use social interactions to improve their Arabic. To deal with this issue in Egypt, another approach was established which was to give the students orientation lectures to introduce them to the characteristics of Egyptian society and social customs as soon as they started the course (Nahla, 2006).

\section{Conclusion}

This paper has presented a review of the literature on Arabic language programmes beginning with a brief review of the historical background of TAFL and its challenges, and followed by a description of the Arabic language and its characteristics. Additionally, factors that affect the learning of Arabic, such as linguistic and pedagogical factors have been presented.

The conclusion to draw from this paper is that the Arabic language is clearly attracting attention worldwide; however, enormous problems in teaching Arabic as a foreign language need to be considered, and scholars in the field need to make a concerted effort to improve the profession.

It seems that some of the difficulties and challenges are likely to be due to specific features of the Arabic language itself. This is possibly due to the radical difference between spoken Arabic dialects and the official written language taught in school and used for academic materials.

Additionally, having different Arabic programmes in different universities shows that there is no agreement as to what kind of Arabic should be taught in Arabic programmes. Even in the case of providing the two forms of Arabic, Modern Standard Arabic and a chosen dialect, there is no agreement about which form to start with and which dialects should be taught. This fundamental question still needs to be answered by applying empirical research that will help our understanding of this issue. Although some of the studies that have sought to understand students' opinions regarding which form they would like to learn indicate that they prefer learning spoken Arabic (Schmidt, Inbar \& Shohamy, 2004; Palmer, $2007,2008)$, it is vital to select the approach that will best fit students' needs. It is highly 
recommended that the field strategically evaluate these programmes to understand more about the strengths and weaknesses of each approach and to determine which ones (programmes) work better for students. Finding the best approaches that fit students' needs will require constant monitoring and evaluation to ensure programme effectiveness.

It is also vital for students interested in learning both forms of Arabic, (standard and a dialect), to balance and bridge the difficult gap between written and spoken skills by providing the two forms of Arabic concurrently. Although this approach poses inherent difficulties in some programmes, thoughtfully designed and carefully implemented combinations of the two forms can provide a more comprehensive and accurate understanding of the Arabic language.

The challenges that face Arabic programmes can also be attributed to the lack of a systematic approach to the integration of Arabic culture as an important factor for language competence. Developing such an integrated approach remains one of the most pressing challenges that the field faces at this time. Therefore, it is important to consider that teaching Arabic should not just be limited to classes, but should also involve organizing seminars and lectures for students to clarify aspects of Arab culture and civilization and to shed light on the cultural differences between their own societies and Arab society.

Although the previous research has provided evidence enabling one to understand the factors behind Arabic learning difficulties, the majority of these findings have been based on studies involving native speakers of English. Thus, this research is not necessarily valid for speakers of other languages. It must be kept in mind that the difficulty in learning Arabic might be largely related to other factors such as the extent of similarity between Arabic and one's own native language or other languages one has previously studied. Furthermore, difficulties in learning Arabic could be related to what students believe about Arabic culture, the learning context, and the quality of the programmes and students' prior knowledge. Therefore, more research is needed in this field. In particular, there is an urgent need for research that seeks to understand how Arabic could be learnt despite these challenges and what could be done to facilitate such learning.
Finally, it is suggested that the field of Arabic language education cannot be improved unless policy makers in Arab countries are aware of the importance of improving the quality of Arabic as a foreign language programmes. The first step might be by establishing a clear policy or vision for teaching and learning Arabic as a foreign language.

\section{References}

Abboud, P. (1995). The teaching of Arabic in the United States: Whence \& whither? In M. Al-Batal (Ed.), The teaching of Arabic as a foreign language: Issues and directions (pp.13-33). Provo, UT: American Association of Teachers of Arabic.

Abdelhadi, S., Ibrahim, R., \& Eviatar, Z. (2011). Perceptual load in the reading of Arabic: Effects of orthographic visual complexity on detection. Writing Systems Research, 3(2), 117-127. doi: 10.1186/17449081-8-3.

Abu-Hatab, W. (1992). Error analysis of compositions written by Community College students. Unpublished Master dissertation. University of Jordan, Amman, Jordan.

Agius, D. A. (Ed.), (1990). Diglossic tension: Teaching Arabic for communication. Leeds, England.: Folia Scholastic.

Al-Batal, M. (1988). Towards cultural proficiency in Arabic. Foreign language Annals, 21(5), 443-448.

Al-Batal, M. (1992). Diglossia proficiency: The need for an alternative approach to teaching. In A. Rouchdy, (Ed.), The Arabic language in America (pp.284-304). Detroit, MI: Wayne State University Press.

AL-Batal, M. (1995a). The Arabic teaching profession: Current realities and future challenges. In M. Al-Batal, (Ed.), The teaching of Arabic as a foreign language: Issues and directions (pp.1-11). Provo, UT: American Association of Teachers of Arabic.

Al-Batal, M. (1995b). Issues in the teaching of the productive skills in Arabic. In M. AlBatal, (Ed.), The teaching of Arabic as a foreign language: Issues and directions (pp.115133). Provo, UT: American Association of Teachers of Arabic. 
Al-Batal, M. (2007). Arabic and national language education policy. Perspectives. The Modern Language Journal. 91(2), 268-271.

Al-Batal, M., \& Belnap, R. (2006). The teaching and learning of Arabic in the United States: Realities, needs, and future directions. In K. Wahba, Z. Taha, \& L. England, (Eds.), Handbook for Arabic language teaching professionals in the 21st century (pp.389-399). Mahwah, New Jersey: Lawrence Erlbaum Associates, Inc.

Al-Hamad, F. (1983). Problems in teaching Arabic to foreigners. In O. Jonathan, \& A. Issam, (Eds.), Proceedings of the second Annual linguistics conference (pp.81-100). Yarmouk University, Irbid, Jordan.

Al-Juhany, A. (1990). Problems and solutions of teaching Arabic to speakers of other languages. Unpublished doctoral dissertation. Islamic University of Medina, city? Kingdom of Saudi Arabia.

Al-Khatib, M. (2000). The Arab world: Language and cultural issues. Language, Culture and Curriculum, 13(2), 121-125.

Allen, R. (1987). The Arabic guidelines: Here now? In S. Charles, \& H. Chip, (Eds.), ACTFL proficiency guidelines for the less commonly taught languages. Washington, DC: The Center for Applied Llinguistics $\&$ ACTFL. American Council on the Tteaching of Fforeign Llanguage (ACTFL).1989. Foreign Language Annals, 22(4), 373-392.

Allen, R., \& Allouche, A. (1986). Let's learn Arabic: A proficiency-based syllabus for Modern Standard Arabic. Philadelphia, PA: University of Pennsylvania Press.

Allen, R. (2007). Arabic-flavor of the moment: Whence, why and how? The Modern Language Journal. 91(2), 258-261.

Al-Mutawa, N. (1995). Challenges facing learners of Arabic as a foreign language at Al-Kuwait University. The College of Education Journal, 2, 12-20.

Alosh, M. (1997). Learner, text and context in foreign language acquisition: An Arabic perspective, pathways to advanced skills series. The Ohio State University National Foreign Language Resource Centre. If a book you need city and state.
Al-Tueriqy, M. (1988). A field study of the major problems facing non-native speakers of Arabic. Unpublished Master dissertation, Islamic University in Medina,city?Kingdom of Saudi Arabia.

Anghelescu, N. (2006). The Arabic language at the University of Bucharest. In K. Wahba, Z. Taha, \& L. England, (Eds.), Handbook for Arabic language teaching professionals in the 21st century (pp.115-122). Mahwah, New Jersey: Lawrence Erlbaum Associates, Inc.

Awde, N., \& Samano, P. (1986). The Arabic alphabet: How to read and write it. London, England: Saqi Books.

Beeston, A. (1968). Written Arabic: An approach to the basic structures. Cambridge, England: Cambridge University Press.

Belnap, R. (1987). Who's taking Arabic and what on earth for? A survey of students in Arabic language programmes. AlArabiyya, 20, 29-42.

Belnap, R. (1995). The institutional setting of Arabic language teaching: A survey of programme coordinators and teachers of Arabic in U.S. institutions of higher learning. In M. Al-Batal, (Ed.), The teaching of Arabic as a foreign language: Issues and directions (pp.34-78). Provo, UT: American Association of Teachers of Arabic.

Belnap, R. (2006). A profile of students of Arabic in U.S. universities. In K. Wahba, Z. Taha, \& L. England, (Eds.), Handbook for Arabic language teaching professionals in the 21st century (pp.389-399). Mahwah, New Jersey: Lawrence Erlbaum Associates, Inc.

Burj, T. (1978). The difficulties facing learners of Arabic as a foreign language: Scientific and practical solutions. Proceedings of the first international symposium on teaching Arabic to non-Arabic speakers. 2, (pp.131151), King Saud University, Al-Riyadh, The Kingdom of Saudi Arabia or Saudi Arabia.

Cote, R. (2009). Choosing one dialect for the Arabic speaking world: A status planning dilemma. Arizona Working Papers in SLA $\mathcal{E}$ Teaching, 16, 75- 97. Retrieved October 10, 2009 from http://w3.coh.arizona.edu/awp. 
Dickins, J, and Watson, J. (2006). Arabic Teaching in Britain and Ireland. In Kassem M, Wahba, Zeinab A. Taha and Liz England (eds) Handbook for Arabic Language Teaching Professionals in the 21st Century. Mahwah, NJ: Lawrence Erlbaum Associates. pp. 107-114.

Eisele, J. (2006). Developing frames of reference for assessment and curricular design in a diglossic L2: From skills to tasks (and back again). In K. Wahba, Z. Taha, \& L. England, (Eds.), Handbook for Arabic language teaching professionals in the 21st century (pp.197-220). Mahwah, NJ: Lawrence Erlbaum Associates, Inc.

Elgibali, A., \& Taha, Z. (1995). Teaching Arabic as a foreign language: Challenges of the nineties. In M. Al-Batal, (Ed.), The teaching of Arabic as a foreign language: Issues and directions (pp.79-102). Provo, UT: American Association of Teachers of Arabic.

Ferguson, C. A. (1959). Diglossia. Word, 15, 325-340.

Fragman, A., \& Russak, S. (2010). A qualitative analysis of spelling errors in Arabic as a foreign language among native $\mathrm{He}-$ brew speaking students. Teaching and learning the Arabic language, pp. 103114.

Haeri, N. (2000). Form and ideology: Arabic sociolinguistics and beyond. Annual Review of Anthropology, 29, 61-87.

Hansen, G. F. (2010). Word recognition in Arabic as a foreign language. The Modern Language Journal, 94(4), 567-579. doi:10.1111/j.1540-4781.2010.01094.x.

Harvey, D. (1979) Spoken Arabic. CS: Hodder \& Stoughton.

Heath, P. (1990). Proficiency in Arabic language learning: some reflections on basic goals. Al-Arabiyya, 23, 31-48.

Holes, C. (1995). Modern Arabic: Structures, functions and varieties. London, England: Longman.

Ibrahim, M. H. (2001). Communicating in Arabic: Problems and prospects. In C. Florian, (Ed.), Language Adaptation (pp.39-59). Cambridge, England: Cambridge University Press.
Ibrahim, R., Khateb, A., \& Taha, H. (2013). How does type of orthography affect reading in Arabic and Hebrew as first and second languages? Scientific Research, 3(1), 40-46. doi: 10.4236/ojml.2013.31005.

Killean, C. (1997). Learning Arabic: A lifetime commitment. In A. Afsaruddin, \& M. Zahniswe, (Eds.), Humanism, culture, and language in the Near East: Studies in Honor pf Georg Krotkoff (pp.145-154). Winona Lake, State?: Eisenbrauns.

Lambert, R. (1992). Foreign language planning in the United States. NFLC Occasional Papers. Washington, DC: The National Foreign Language Center.

Liskin-Gasparro, J. (1982). ETS Oral proficiency testing manual. Princeton, NJ: Educational Testing Service.

Maamouri, M. (1998). Arabic diglossia and its impact on the quality of education in the Arab region. A paper presented at The World Bank Mediterranean Development Forum, Marrakech, Morocco (September 3-6)

Madkoor, A. (2007). Teaching Arabic as a foreign language. Cairo, Egypt: Dar Alfikr AlArabi.

McCarus, E. N. (1987). The Study of Arabic in the United States: A history of its Development. Al-Arabiyya, 20, 13-27.

McCarus, E. (1992). History of Arabic study in the United States. In Aleya Rouchdy (Ed.), The Arabic language in America (pp. 207-221). Detroit, MI: Wayne State University Press.

Myhill, J. (2014) The Effect of Diglossia on Literacy in Arabic and Other Languages in E. Saiegh-Haddad, R. M. Joshi (eds.), Handbook of Arabic Literacy, Literacy Studies (197-223 ) Springer Science \& Business, Media Dordrecht 2014.

Nash, A. (2010) Critical issues of Arabic learning and teaching, an interview with Michael Cooperson. Issues in Applied Linguistics, 18(1), 125-139.

Nahla, M.A. (2006). Teaching Arabic to nonnative speakers at Alexandria University. In K. Wahba, Z. Taha, \& L. England, (Eds.), Handbook for Arabic language teaching professionals in the 21st century (pp.67- 
79). Mahwah, NJ: Lawrence Erlbaum Associates, Inc.

Nicola, M. (1990). Starting Arabic with dialect. In D. Aguis, (Ed.), Diglossic tension: Teaching Arabic for communication (pp.4245). Beaconsfield Papers. Leeds, England: Folia Scholastica.

Palmer, J. L. (2007). Arabic diglossia: Teaching only the standard variety is a disservice to students. Arizona Working Papers in Second Language Acquisition and Teaching, 14. Online at http://w3.coh.arizona.edu/awp/Volum es.htm

Palmer, J. L. (2008). Arabic diglossia: Student perceptions of spoken Arabic after living in the Arabic-speaking world. Arizona Working Papers in Second Language Acquisition and Teaching, 15, 81-95. Online at http://w3.coh.arizona.edu/awp/ . don't switch to and from italics.

Ryding, K. (1994). Fostering a learning community for Arabic. Theory into Practice, 33(1), 23-28.

Ryding, K. (1995). Discourse competence in TAFL: Skill levels and choice of language variety in the Arabic classroom. In M. AlBatal, (Ed.), The teaching of Arabic as a foreign language: Issues and directions (pp.115133). Provo, UT: American Association of Teachers of Arabic.

Ryding, K. (2006). Teaching Arabic in the United States. In K. Wahba, Z. Taha, \& L. England, (Eds.), Handbook for Arabic language teaching professionals in the 21st century (pp.13-20). Mahwah NJ: Lawrence Erlbaum Associates, Inc.

Saiegh-H., initial? \& Henkin- R. (2014). The Structure of Arabic Language and Orthography. In E. Saiegh-Haddad, R. M. Joshi (eds.), Handbook of Arabic Literacy, Literacy Studies (3-28).

Siti Ikbal S. S. (2006). The problem of Arabic speaking skill among the students of religious secondary schools in Selangor. In M. Rosdi Ismail, \& M. Taib Pa (Eds.), The teaching and learning of Arabic Language in Malaysia.Kuala Lumpur: city, country: University Malaya publications.

Stevens, P. B. (2006). Is Spanish really so easy? Is Arabic really so hard? Perceived difficulty in learning Arabic as a second language. In K. Wahba, Z. Taha, \& L. England, (Eds.), Handbook for Arabic language teaching professionals in the 21st century (pp.34-63). Mahwah, NJ: Lawrence Erlbaum Associates, Inc.

Suleiman, Y. (1993). TAFL and the teaching/learning of culture: Theoretical perspectives and an experimental module. Al-Arabiyya, 26, 61-111.

Suleiman, Y. (2003). The Arabic language and national identity. Washington, DC: Georgetown University Press.

Taaima. R., \& Al-Naqa, K. (2006). Teaching Arabic communicatively: Instructions and strategies. AL- Rabat, Morocco: Islamic Educational Scientific Cultural Organization (ISESCO).

Taha, Z. (2006). Toward pragmatic competency in Arabic. In K. Wahba, Z. Taha, \& L. England, (Eds.), Handbook for Arabic language teaching professionals in the 21st century (pp. 343-361). Mahwah, NJ: Lawrence Erlbaum Associates, Inc.

Van Mol, M. (2006). Arabic receptive language teaching: A new CALL approach. In K. Wahba, Z. Taha, \& L. England, (Eds.), Handbook for Arabic language teaching professionals in the 21st century (pp. 305-314). Mahwah, NJ: Lawrence Erlbaum Associates, Inc.

Versteegh, K. (2006). History of Arabic language teaching. In K. Wahba, Z. Taha, \& L. England, (Eds.), Handbook for Arabic Language teaching professionals in the 21st century (pp.3-12). Mahwah, NJ: Lawrence Erlbaum Associates, Inc.

Wahba. K.M. (2006). Arabic language use and the? educated language user. In $\mathrm{K}$. Wahba, Z. Taha, \& L. England, (Eds.), Handbook for Arabic language teaching professionals in the 21st century (pp.139-155). Mahwah, NJ: Lawrence Erlbaum Associates, Inc.

Younes, M. (1995). An integrated curriculum for elementary Arabic. In M. Al-Batal, (Ed.), The teaching of Arabic as a foreign language: Issues and directions (pp.233255). Provo, UT: American Association of Teachers of Arabic. 